\title{
INFLUENCIA DE LOS PROFESIONALES SANITARIOS EN LA SOLICITUD DE DONACIÓN
}

\section{INFLUENCE OF THE SANITARY PROFESSIONALS IN THE REQUEST OF DONATION}

\author{
*Segovia, Carmen \\ * Enfermera. Monitora del Curso de Comunicación de Malas Noticias de la ONT. Madrid. \\ Palabras clave: Comunicación de malas noticias, solicitud de donación. \\ Keywords: Communication of bad news, Request of donation.
}

\begin{abstract}
RESUMEN
La comunicación de malas noticias es una tarea generadora de tensión en los profesionales de la salud, a la vez que un acto tremendamente humano, ético, médico y legal. En los últimos años la transmisión de esta información ha ido evolucionando desde una actitud paternalista a una relación basada en el consentimiento informado, que recoge nuestra Ley General de Sanidad. El proceso de donación se encuentra inmerso en el proceso de comunicación de la peor de las noticias, la muerte, y producida la mayoría de las veces de manera súbita. Estudios realizados en hospitales europeos, indican que el contacto con familias de pacientes críticos es una fuente generadora de tensión para el profesional de enfermería. Nuestro objetivo se centra en presentar las consecuencias de esa comunicación y exponer cómo llevarla a cabo dentro de una Relación de Ayuda a la familia.
\end{abstract}

\section{ABSTRACT}

The communication of bad news is an stress generating task for the health professionals and, at the same time, an important human, ethical, medical and legal action. Last years, news transmission has evolved from a paternalistic attitude to an informed consent based relation, covered by our Health General Law. The donation process is immersed in the worst news communication process, the death, and most of the time produced suddenly. Studies made at European hospitals, show that the contact with families of critical patients is an stress generating source for the nursing professional. Our aim is showing the consequences of that communication and presenting how to drive it in a Helping Relationship to the family. 
La comunicación de malas noticias es una de las tareas, si no la que más, generadora de tensión en los profesionales de la Salud.

Marcos Gómez Sancho define la comunicación de una mala noticia como "un acto, humano, ético, médico y legal. Que un ser humano tenga que comunicar a otro que su muerte o la de alguno de los suyos están próximas, es a la fuerza un acto tremendamente humano. Es el momento de mayor grandeza del acto médico y uno de los más difíciles".

En los últimos años, afortunadamente ha ido cambiando la mentalidad en cuanto a la relación de los profesionales con los pacientes respecto a la información sobre el diagnóstico, la evolución de la enfermedad, el tratamiento a seguir, etc. Ha ido evolucionando desde una actitud paternalista a una relación basada en el consentimiento informado.

Este derecho a la información, recogido en la Ley General de Sanidad, es compartido y aceptado por los profesionales de la Salud, en tanto en cuanto el paciente tiene una alternativa terapéutica y/o curativa. Cuando un paciente y su familia están bien informados, sabemos que tendremos más posibilidad de que haya más adhesión al tratamiento y colabore mejor. Sin embargo, cuando se trata de comunicar malas noticias: un mal pronóstico, o incluso la muerte, la situación cambia sobremanera. Teniendo en cuenta que los profesionales de la Salud consideramos la muerte como un fracaso, comunicar una mala noticia es algo que siempre nos gustaría que otro ocupara nuestro lugar; anunciar a un paciente que las cosas están yendo bien, siempre es agradable, pero transmitir un fracaso terapéutico o incluso la muerte, es una de las situaciones que generan más tensión en los profesionales, entre otras cosa porque sabemos que va a producir en la familia reacciones de difícil control y manejo.

El proceso de donación se encuentra inmerso en el proceso de comunicación de la peor de las noticias, la muerte, una muerte producida la mayoría de las veces de manera súbita, y en este contexto, para la familia supone un gran impacto emocional, hay resistencia natural a aceptar la pérdida, está presente de manera importante la negación a aceptar la muerte del ser querido, se hace muy difícil integrar y asimilar información y hay grandes problemas para la toma de decisiones.

Respecto a los profesionales sanitarios, en un estudio multicéntrico realizado en hospitales europeos, indicaban que el contacto con familias de pacientes críticos les suponía una fuente generadora de tensión por la falta de estrategias a la hora de afrontar el contacto con este tipo de familias, además de no saber qué hacer o decir en esos momentos. Gran parte de estos profesionales reconocían evitar a menudo el contacto con las familias por temor a aumentarles el dolor. Indicaban tener prejuicios en estas situaciones que les dificultaban la interacción, tales como sentirse intrusos en esos momentos de dolor, o pensar que los profesionales estamos para tratar, cuidar al paciente, pero que no tenemos nada que ofrecer a las familias.

Según datos extraídos de los cuestionarios de valoración del Curso de Comunicación de Malas Noticias de la ONT, de los 6169 cuestionarios analizados, al $59 \%$ de los profesionales les resulta estresante o muy estresante comunicarse con las familias de los pacientes críticos; es curioso que cuando se les pregunta en qué medida les resulta difícil comunicarse con las familias de potenciales donantes, este porcentaje aumenta al $78 \%$. 
Algo aparece en el sentir de los profesionales cuando aumenta esta percepción.

Este ultimo dato refrenda un estudio realizado a dos grupos de enfermeras. Un primer grupo manifestaban sentirse "seguras" a la hora de solicitar la donación de los órganos de un paciente a su familia y obtenían un $84 \%$ de consentimiento familiar, por el contrario otro grupo de enfermeras que manifestaban reticencias respecto a la donación de órganos no consiguieron que ninguna de las familias accediera a donar. Sin embargo, para este mismo grupo de enfermeras, cuando se trataba de solicitar tejidos, el $42 \%$ de las familias accedieron a donar. Uno de los factores que influyeron en este segundo grupo, en la obtención de tejidos, cuando a la hora de solicitar órganos ni una sola de las familias accedió a donar, fue que cuando solicitaban órganos lo hacían a familias cuyo ser querido había fallecido en muerte encefálica y se sentían incómodas a la hora de manejar y responder a sus dudas.

Diferentes estudios analizan la existencia de demandas, en relación no tanto con la existencia o no de mala praxis, sino en relación con la comunicación. Un estudio realizado por Wendy Levinson, investiga la comunicación en relación con las demandas. Realizó un estudio a dos grupos de médicos, grabando las conversaciones con sus pacientes: la mitad de ellos habian tenido al menos dos denuncias y a la otra mitad nunca les habían demandado. Según el estudio, Levinson concluye que los médicos con menos quejas de los pacientes son los que escuchan sin interrupciones, les animan a hacer preguntas y practican la escucha activa.

Posteriormente, y a partir del estudio de Levinson, la psicóloga Nalili Ambady analizó las grabaciones, seleccionado fragmentos en los que hablaba el médico, filtrando las cintas de tal manera que lo que se escuchaba no era lo que el médico decía, sino cómo lo decía. Estos fragmentos fueron escuchados por un grupo de personas que puntuaban según parámetros tales como la observación del afecto, la hostilidad, la dominación y la ansiedad, y descubrió que tan sólo con el uso de estas categorías se podía deducir qué médicos eran los demandados y cuales no.

Cuando se trata de familias de potenciales donantes, si la familia no se ha sentido bien informada, o ha percibido mal trato, es más que probable que, al menos inicialmente, haya una respuesta negativa a la donación. Testimonios de familias donantes, relacionan una mala comunicación o la percepción de mal trato, con la negativa a donar. A la inversa, familias que no eran favorables a la donación, manifiestan haber donado en base a la confianza y a una buena información en ese marco.

Es importante aprender a entenderse con los demás, ya que pasamos nuestra vida relacionándonos con nuestro entorno, conocer ciertas habilidades de comunicación nos ayuda a mejorar las relaciones interpersonales, manifiesta seguridad y confianza en la relación y posibilita una mejora en la percepción del usuario de la calidad de nuestros servicios.

La comunicación de la raíz latina "communicare", poner en común, en su forma más sencilla se trata del intercambio de mensajes entre personas involucradas en un proceso de comunicación y que están interactuando continuamente.

El emisor emite un mensaje que es decodificado por el receptor del mismo, por lo tanto la acción de una persona favorece la respuesta de la otra, es por lo tanto un continuo intercambio de elementos que funcionan como estímulo y elementos que funcionan como 
respuesta. La causa más importante de fracaso en la comunicación, estriba en asumir que el mensaje que se emite ha sido decodificado por el receptor.

Podríamos decir que en la comunicación hay dos niveles:

- Nivel Denotativo: Indica lo que se dice con las palabras, es decir el contenido del mensaje que se quiere comunicar.

- Nivel Meta-Comunicativo: Se refiere a los elementos no verbales. Proporciona información adicional para interpretar correctamente el mensaje

Es imposible no comunicar, constantemente estamos emitiendo conductas y nuestras actitudes son mensajes para otros. Incluso aunque no queramos comunicarnos, estamos con ello transmitiendo un mensaje para los demás.

En este fragmento de "La Muerte Intima de Marie de Hennezel" queda reflejada la percepción angustiosa de un paciente terminal de cómo está siendo tratado.

"Entran diez médicos en tu habitación. Te dan la mano con total indiferencia y se ponen a discutir entre ellos sobre el tratamiento a seguir contigo como si tú no estuvieras delante. El médico jefe le pregunta a la supervisora si has hecho deposición, si duermes bien, si has vomitado... se preguntan y se responden el uno al otro estando tú ahí ¡como si fueras tonto!. Mientras los residentes se ponen a mirar por la ventana con los ojos perdidos en el horizonte para no encontrarse con tu angustiosa mirada.

Sientes que se pronuncian palabras ininteligibles que parecen referirse a la puesta en marcha de un nuevo tratamiento a ver si con esto.... Y entonces, dan media vuelta y se van. Sin que haya habido nadie con un mínimo de humanidad para sentarse unos minutos a tu lado y preguntarte como llevas tu enfermedad".

Queda reflejado en este fragmento que las actitudes, los comportamientos, son mensajes para otros.

La comunicación sanitaria tiene el carácter de ayuda profesional y tiene como objetivo facilitar al paciente y la familia, la expresión de sus pensamientos y deseos. Una buena comunicación sanitaria lleva implícito el desarrollo de la Relación de Ayuda: Carl Rogers, padre de la Relación de Ayuda la define como "Aquella relación que se produce entre dos personas, en las que una de las partes, intenta hacer surgir en la otra recursos y capacidades latentes con el fin de afrontar los problemas de la forma mas adecuada y resolutiva posible". Es una relación terapéutica, que se produce en una situación cara a cara, pretende buscar soluciones a los problemas inmediatos que plantea una nueva situación y la persona que ayuda, realiza un acompañamiento activo.

Se basa en tres pilares elementales:

- El Respeto cálido

- La Empatía

- La Autenticidad

El Respeto Cálido es la aceptación incondicional y la valoración de la persona como un ser único y capaz de elegir la conducta más adecuada en cada momento. Implica la ausencia de juicios moralizantes, implica confianza, acogida y cordialidad en el trato. 
La Empatía es la comprensión básica de la escucha. Empatía es ser capaz de ponerse en el lugar del otro y entender sus sentimientos, actitudes y comportamientos, es ser capaz de leer emocionalmente a las personas. Exige la capacidad de, desde una cierta distancia, ser capaz de meterse en la vivencia del otro aunque solo sea temporalmente.

La Autenticidad es un ajuste interno entre lo que se es, y lo que se comunica, por lo que debe ir acompañada del Canal de Comunicación No Verbal (CNV), ya que además de ser el canal de comunicación que expresa los sentimientos, cuando los dos canales de comunicación se contradicen, el que predomina es el CNV.

La Relación de Ayuda, se enmarca dentro de la Escucha Activa. Escuchar no es algo que dependa sólo de nuestra agudeza auditiva. Hay una gran diferencia entre oír y escuchar. Oír es percibir vibraciones de sonido y es un acto involuntario. Escuchar es un acto consciente y voluntario que implica un mayor esfuerzo, es entender y dar sentido a lo que estamos oyendo.

Cuando escuchamos activamente no lo hacemos sólo con los oídos. Escuchamos con la observación del otro, para entender sus mensajes no verbales:

- Escuchamos con el cuerpo

- Escuchamos con los sentidos

- Escuchamos con el uso de monosílabos

- Escuchamos sobre todo con el silencio

Por lo tanto todas las técnicas de comunicación efectivas parten de la práctica de la escucha activa.

Todas las técnicas de comunicación efectivas parten de la Escucha Activa, algunas se dirigen a la parte afectiva del mensaje, como el Reflejo de las emociones, que lo que persigue es hablar el lenguaje de los sentimientos del otro. Se centra en su estado emocional, comunicándole que se le acepta y se le comprende desde la escucha. Otras se dirigen al mensaje como la reformulación o la clarificación, que lo que persiguen, además de hacer saber a la familia que se le escucha y se le comprende, es animarle a hablar y aclarar los contenidos.

Aunque las preguntas requieren un cierto clima de confianza, también forman parte de las técnicas de comunicación, y aunque el objetivo es proporcionar información, al menos inicialmente se deben plantear centrándolas más en los intereses del otro más que en los propios.

El nivel Meta- Comunicativo lo forma el Canal de Comunicación no Verbal, va en relación directa con uno de los pilares de la Relación de Ayuda, la Autenticidad, sobre todo porque cuando se contradicen los dos canales de comunicación, es el que predomina. Transmite las actitudes interpersonales, los sentimientos y las emociones, según Mehrabian aproximadamente el 60-70\% de los mensajes son de naturaleza no verbal, y esta tesis avala el estudio de Levinson, pero no deja de ser importante que la mayoría de ellos son captados y emitidos de manera involuntaria.

Elementos de la CNV utilizados de manera adecuada, tales como la postura, expresión facial, la mirada, etc, transmiten calidez en la interrelación, así como los elementos no 
verbales del habla, el tono de voz, la utilización de las pausa y el ritmo del lenguaje facilitan la comprensión del mensaje verbal transmitiendo al mismo tiempo apoyo.

Utilizando en definitiva los dos canales de comunicación pone los cimientos de una comunicación eficaz, como dice Mario Benedetti, en su Antología Poética: "Mi táctica es hablarte y escucharte, construir con palabras un puente indestructible".

Todo esto en un entorno adecuado. Cuando se trata de comunicar malas noticias el entorno adquiere una relevancia especial, una buena noticia se puede dar en cualquier lugar, una mala noticia precisa seriedad y protocolo y realizada en el lugar adecuado amortigua el impacto de la misma, al igual que realizada en el lugar inadecuado y de la forma inadecuada potencia el impacto.

A modo de resumen hay elementos que facilitan la Relación de Ayuda:

- Personalizar

- Respetarle cualquier tipo de reacción

- Dar un trato cordial y abierto

- Respetar los silencios

- Mostrar paciencia

- No transmitir prisa. Gestionar el tiempo

- Evitar el uso de tecnicismos

- Mensajes cortos, frases estructuradas y breves

- Respetar el ritmo de asimilación

- Consolar el dolor, facilitando la expresión de emociones, no coartarlas

- Dar oportunidad de hacer preguntas

- Ser conscientes de los temores y preocupaciones de las familias

Qué elementos dificultan la Relación de Ayuda

- Cambiar de tema

- Interrumpir

- Frivolizar o minimizar

- Decirle lo que debe hacer o sentir

- Hacer juicios morales o censurar

- Dar consejos que no se solicitan

- Manifestar prisa

- Prometer nada que no se esté en disposición de cumplir

En principio podría pensarse que la utilización de las técnicas de comunicación podría restar naturalidad al comportamiento, sin embargo, y al igual que la práctica de técnicas instrumentales nos proporciona la seguridad, la práctica continuada de las habilidades de comunicación facilita incorporar estos hábitos a la propia personalidad.

Es importante la formación de los profesionales de la Salud en habilidades y técnicas comunicativas. Sobre todo cuando se trata de comunicar malas noticias además de proporcionar seguridad, mejora la situación de tensión y posibilita una mejora de la percepción del usuario de la calidad de nuestros servicios.

Un proceso de comunicación adecuado amortigua el impacto de la mala noticia, y en el caso de familias de potenciales donantes, es facilitador del adecuado clima de confianza en el que se tiene que desarrollar la entrevista de donación. 
